\title{
Incontinentia pigmenti in a term neonate: an atypical presentation
}

This article was published in the following Dove Press journal:

Research and Reports in Neonatology

\section{Sasi Bhushan Gottimukkala Madhu Jagalasar \\ Giridhar Sethuraman \\ Srinivasan Kitchanan \\ Department of Neonatology, Chettinad Hospital \& Research Institute, Chennai, Tamil Nadu, India}

Correspondence: Giridhar Sethuraman Department of Neonatology, Chettinad Hospital \& Research Institute, Rajiv Gandhi Salai, Kelambakkam, Kanchipuram District, Chennai, Tamil Nadu, India 603103

Tel +9l 9841027228

Email giridharsethu@gmail.com
Abstract: Incontinentia pigmenti is a rare X-linked dominant multi-system disorder that is clinically suspected, based on the characteristic evolution of skin lesions through four stages. We describe a term neonate who presented at birth with pleomorphic skin rashes, including linear hyperpigmented hyperkeratotic lesions and erythematous vesicles, and then developed seizures. She was later histologically and genetically confirmed as a case of incontinentia pigmenti. The simultaneous presence of three stages of skin lesions in the neonatal period is an atypical presentation, which has not been previously well described.

Keywords: incontinentia pigmenti, IKBKG gene, seizures, infant, newborn

\section{Introduction}

Incontinentia pigmenti (IP) is a rare $\mathrm{X}$-linked dominant disorder that is caused by a mutation in the inhibitor of nuclear factor kappa B [NF- $\mathrm{\kappa B}$ ] kinase subunit gamma $(I K B K G)$ gene located on Xq28. ${ }^{1}$ Defective activation of $\mathrm{NF}-\mathrm{\kappa B}$ results in apoptosis of ectodermal and mesodermal tissues causing multisystem involvement. IP is suspected based on characteristic skin eruptions occurring along Blashko lines. These lesions slowly evolve from erythematous vesicopustules in the neonatal period to hyperkeratotic, verrucous papules, and plaques in infancy followed by hyperpigmention and then hypopigmentation. ${ }^{2}$ Histopathological evaluation of skin lesions reveal marked eosinophilia. ${ }^{3}$ Other tissues involved in IP are hair, teeth, nails, eyes, and central nervous system (CNS). CNS involvement occurs in 33\%-50\% of the cases and usually presents as focal neonatal seizures. ${ }^{4}$ We describe a neonate who presented with pleomorphic skin rashes and seizures, that were later histologically and genetically confirmed as IP. The simultaneous presence of multiple skin stages in the neonatal period is the atypical presentation.

\section{Case report}

A 3,040 g girl was born via a normal vaginal delivery to a healthy primigravida mother, after an uncomplicated pregnancy at term. The baby was $48 \mathrm{~cm}$ tall (50-90 percentile) with a head circumference of $33.5 \mathrm{~cm}$ (50-90 percentile). At birth, linear hyperpigmented hyperkeratotic lesions were observed on the upper and lower extremities. Crops of erythematous vesicles were also noticed over the thorax, abdomen and groin (Figure 1). Some vesicles healed over the groin over the next 3 days, but the warty lesions persisted. On day 4 of life, the baby developed multifocal clonic seizures involving the right hand and leg and received phenobarbital and fosphenytoin for seizure control. The laboratory 


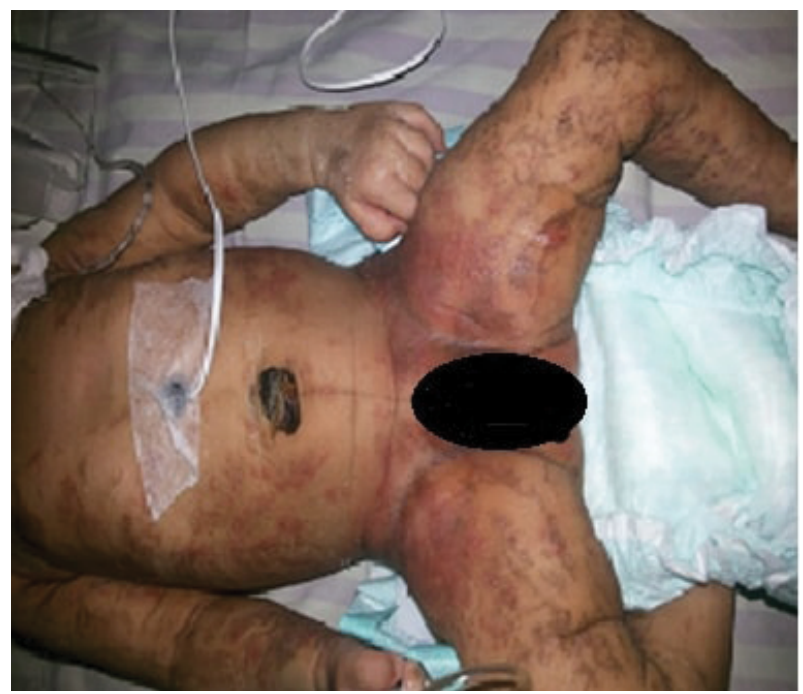

Figure I Hyperpigmented hyperkeratotic lesions and erythematous vesicles seen at birth.

tests showed no abnormalities in complete blood picture, serum electrolytes, glucose, prothrombin time, activated partial thromboplastin time, calcium, magnesium, ammonia and c-reactive protein. Furthermore, echocardiography, serologic tests for toxoplasmosis, rubella, cytomegalovirus, and herpes simplex virus infection, and metabolic screening tests were normal. The electroencephalogram showed epileptiform discharges in the right cerebral hemisphere. In view of the pleomorphic skin eruptions and seizures, and common infectious etiologies being ruled out, IP was suspected. A biopsy of a vesicle on the arm showed epidermal spongiosis with numerous eosinophils within the epidermis (eosinophilic spongiosis), eosinophil filled intra-epidermal blisters and some dyskeratotic keratinocytes, a picture consistent with the vesicular stage of IP (Figure 2). Diffusion weighted imaging showed gyriform high-signal-intensity lesions in the parietal and occipital lobes of the cerebrum suspected of being bilateral non-hemorrhagic infarctions. The seizures ceased by day 12 of life. Later, molecular genetic analysis showed deletion mutation of the $I K B K G$ gene, confirming IP. Parental testing was advised but it was refused. On follow up at 8 months, the hyperkeratotic skin lesions had disappeared and hyperpigmented whorls or streaks along Blashko lines, more on the trunk, were seen. Neurologically, the child has developmental delay and intermittent seizures and is receiving levetiracetam.

\section{Discussion}

In the neonatal period, IP is clinically diagnosed based on the presence of blaschkoid erythematous linear vesicles, which represents the first stage of skin involvement. These lesions

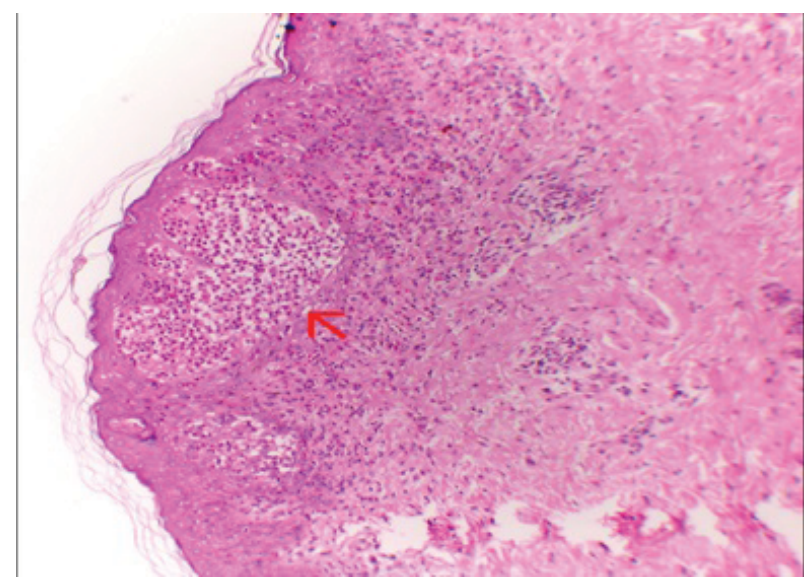

Figure 2 Arrow points to eosinophilic spongiosis with vesicle formation within epidermis in a biopsyspecimen.

are commonly seen at birth or within the first 2 weeks of life. ${ }^{5}$ Common differential diagnosis for first stage of IP is congenital herpes simplex (non-blaschkoid, non-linear). In IP, these lesions gradually evolve into the second stage, characterized by verrucous papules and plaques. The second stage usually appears within 2 months and disappears within 6 months. ${ }^{5}$ The simultaneous presence of both erythematous vesicles and hyperkeratotic pigmented lesions at birth, as in our present case, has been previously reported. ${ }^{6,7}$ The existence of second stage hyperkeratotic lesions with the first stage erythematous vesicles could be explained by the hypothesis that the first stage lesions could have originated in-utero. This explanation is supported by reports showing that the first stage skin lesions are absent in $5 \%-10 \%$ of cases. ${ }^{6}$ The third stage blaschkoid hyperpigmented linear skin lesions are the hallmark of IP, but their onset is highly variable, with some reports showing an appearance in the neonatal period. ${ }^{6,8}$ Onset of blaschkoid hyperpigmented lesions at birth, as in our present case, has also been previously reported and this presentation could similarly be explained by the prenatal onset and evolution of the earlier IP skin stages. ${ }^{8}$ The CNS is involved in $10 \%-30 \%$ IP cases, with seizures being the most common presenting symptom, as in our case. ${ }^{9}$ Blaschkow lines are also seen in other organs such as the brain, explaining the seizures in neonates with IP. The MRI imaging was suggestive of a vascular origin of the CNS insult. MRI showing changes that suggest diffuse vasculopathy in IP patients has been previously well reported. ${ }^{10}$ The atypical pleomorphic skin lesions and inability to rule out an infectious etiology, as in our case, necessitated a skin biopsy for histopathological examination. The marked eosinophilic skin infiltration, as in our case, is a characteristic finding in IP and has hence been proposed as a minor diagnostic criterion. ${ }^{3}$ 
This eosinophilic infiltration, seen in the early stages of IP, is due to an eosinophil-selective, NF- $\kappa \mathrm{B}$-activated chemokine, eotaxin, which is released in the inflammatory cytokines. ${ }^{11}$ Peripheral eosinophilia, which is usually associated with dermal infiltration, was not observed in our case. Other neonatal skin conditions such as erythema toxicum neonatorum and eosinophilic pustular folliculitis can result in eosinophilic skin infiltration, but they can be readily differentiated clinically by their transient non-evolving nature, predominant pustular appearance and non-blaschkoid distribution.

The diagnosis of IP was confirmed by the mutation analysis of the $I K B K G$ gene. Even in the absence of genetic studies, the combination of suspicious blaschkoid skin lesions, CNS manifestations with MRI changes of vasculopathy and eosinophilic skin infiltration in biopsy, is enough to diagnose IP, as per the recent update in the IP diagnostic criteria. ${ }^{5}$ Our case highlights the importance of considering IP, in cases of skin lesions that have a blaschkoid distribution, in spite of having an atypical pleomorphic appearance, especially when associated with neurological manifestations. MRI brain imaging and skin biopsy can aid in the diagnosis. The widespread availability of molecular genetic studies has made the detection of $I K B K G$ mutation in IP an important confirmatory tool, especially in the presence of atypical clinical findings.

\section{Ethics approval}

Written informed consent has been provided by the parents, which includes consent for publishing the condition of the baby, reports and related images.

\section{Acknowledgment}

The authors acknowledge Chettinad Hospital \& Research Institute, Chennai, Tamil Nadu, India.

\section{Disclosure}

The authors report no conflicts of interest in this work.

\section{References}

1. Smahi A, Courtois G, Vabres P, et al. Genomic rearrangement in NEMO impairs NF-kappaB activation and is a cause of incontinentia pigmenti. The International Incontinentia Pigmenti (IP) Consortium. Nature. 2000;405(6785):466-472.

2. Fusco F, Paciolla M, Conte MI, et al. Incontinentia pigmenti: report on data from 2000 to 2013. Orphanet J Rare Dis. 2014;9:93.

3. Hadj-Rabia S, Rimella A, Smahi A, et al. Clinical and histologic features of incontinentia pigmenti in adults with nuclear factor- $\mathrm{\kappa B}$ essential modulator gene mutations. J Am Acad Dermatol. 2011;64(3): 508-515.

4. Goldberg MF. The skin is not the predominant problem in incontinentia pigmenti. Arch Dermatol. 2004;140(6):748-750.

5. Minić S, Trpinac D, Obradović M. Incontinentia pigmenti diagnostic criteria update. Clin Genet. 2014;85(6):536-542.

6. Hadj-Rabia S, Froidevaux D, Bodak N, et al. Clinical study of 40 cases of incontinentia pigmenti. Arch Dermatol. 2003;139(9):1163-1170.

7. Osório F, Magina S, Nogueira A, Azevedo F. Incontinentia Pigmenti with vesicular stage in utero. Dermatol Online J. 2010;16(10):13.

8. Lerer RJ, Ehrenkranz RA, Campbell AG. Pigmented lesions of incontinentia pigmenti in a neonate. J Pediatr. 1973;83(3):503-505.

9. Minić S, Trpinac D, Obradović M. Systematic review of central nervous system anomalies in incontinentia pigmenti. Orphanet $J$ Rare Dis. 2013;8:25

10. Soltirovska Salamon A, Lichtenbelt K, Cowan FM, et al. Clinical presentation and spectrum of neuroimaging findings in newborn infants with incontinentia pigmenti. Dev Med Child Neurol. 2016;58(10): 1076-1084.

11. Jean-Baptiste S, O'Toole EA, Chen M, et al. Expression of eotaxin, an eosinophil-selective chemokine, parallels eosinophil accumulation in the vesiculobullous stage of incontinentia pigmenti. Clin Exp Immunol. 2002;127(3):470-478.
Research and Reports in Neonatology

\section{Publish your work in this journal}

Research and Reports in Neonatology is an international, peer-reviewed, open access journal publishing original research, reports, editorials, reviews and commentaries on neonatal health. The manuscript management system is completely online and includes a very quick and fair

\section{Dovepress}

peer-review system. Visit http://www.dovepress.com/testimonials.php to read real quotes from published authors. 